\title{
Artículos
}

\section{PEDAGOGÍAS DIALÓGICAS EN CONTEXTOS SINDÉMICOS; ACUERPAR EL ACTO EDUCATIVO EN LA REGIÓN NGIGUA POBLANA}

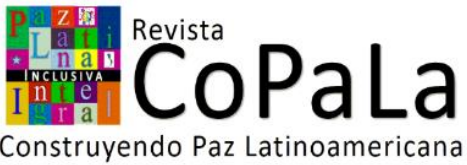

\section{López Varela, Guillermo}

\section{Guillermo López Varela}

guillermo.lopez@uiep.edu.mx

Universidad Intercultural del Estado de

Puebla, México

\section{Revista CoPaLa. Construyendo Paz Latinoamericana}

Red Construyendo Paz Latinoamericana, México

ISSN-e: 2500-8870

Periodicidad: Semestral

vol. 6, núm. 13, 2021

copalarevista@gmail.com

Recepción: 06 Marzo 2021

Aprobación: 29 Mayo 2021

URL: http://portal.amelica.org/ameli/jatsRe po/231/2312167012/index.html

DOI: https://doi.org/10.35600/25008870.2

$\underline{021.13 .0204}$

CRevista CoPaLa, Construyendo Paz Latinoamericana

\section{(c) (i)(2)}

Esta obra está bajo una Licencia Creative

Commons Atribución-NoComercial-

CompartirIgual 4.0 Internacional.
Resumen: El presente artículo es un esfuerzo de sistematización de la experiencia encarnada en estrategias situadas de colaboración tejidas por estudiantes de cuarto semestre de la licenciatura en Lengua y Cultura de la Universidad Intercultural del estado de Puebla en San Marcos Tlacoyalco, teniendo como contexto el grado de letalidad de COVID19 entre los pueblos originarios del estado de Puebla y el índice de vulnerabilidad crítica en que se encuentran los municipios de la región ngigua poblana. Pretendemos brindar algunas claves de lectura, para vislumbrar lo que nosotros llamaremos una "pedagogía del apapacho" en sintonía con los debates de la comunalidad en el corazón de las Universidades Interculturales del estado mexicano con sus ambivalencias, contradicciones y antagonismos vivos $\mathrm{y}$ deseantes para construir una dialógica no totalmente subsumida a la matriz patriarcal, capital y colonial exacerbada por la pandemia de Covid19.

Palabras clave: pedagogía del apapacho, interculturalidad, ngigua, tequio, COVID19.

Abstract: This article is an effort to systematize the experience embodied in situated strategies of collaboration woven by fourth semester students of the Bachelor's Degree in Language and Culture of the Intercultural University of the State of Puebla in San Marcos Tlacoyalco, taking as context the degree of lethality of COVID19 among the native peoples of the State of Puebla and the index of critical vulnerability in which the municipalities of the Ngigua region of Puebla find themselves. We intend to provide some 
keys to reading, to glimpse what we will call a "pedagogy of apapacho" in tune with the debates of communality in the heart of the Intercultural Universities of the Mexican state with its ambivalences, contradictions and living and desiring antagonisms to build a dialogic not totally subsumed to the patriarchal, capital and colonial matrix exacerbated by the pandemic of Covid19.

Keywords: pedagogy of apapacho, interculturality, ngigua, tequio, COVID19. pedagogy of apapacho, interculturality, ngigua, tequio, COVID19.

\section{Introducción}

El estado de Puebla posee la tasa de letalidad de COVID-19 en pacientes provenientes de pueblos originarios más alta de nuestro país. Según datos de la Secretaria de Salud federal (Dirección de información epidemiológica, 2020), en Puebla han fallecido 128 de las 475 personas contagiadas por coronavirus hasta el 31 de diciembre de 2020, fecha del último corte por parte del gobierno federal. Lo anterior significa que la letalidad entre pacientes que se asumen como indígenas en nuestro estado asciende al $27 \%$ aproximadamente, superior a los otros quince estados del país con más casos registrados.

A pesar de que como indica este reporte el 29\% de las defunciones no hayan tenido alguna comorbilidad, el 71\% sí presentaba al menos alguna de ellas. La hipertensión y/o las enfermedades cardiovasculares (30.92\%), así como la diabetes mellitus (28.57\%) o la obesidad (18.59\%), no solo ahora sino desde hace algunas décadas, han sido las principales causas de muerte entre los pueblos originarios. Por ello, en nuestro artículo queremos subrayar, -como viene haciéndolo la administración gubernamental actual-, que las morbilidades de la población en México, no solo tienen que ver con un estilo de vida o un tipo de consumo, sino implican consecuencias profundas de políticas neoliberales de alimentación y atención a la salud.

En este orden de ideas, en el presente artículo responderemos a la cuestión en torno a cuáles podrían ser las innovaciones que aporta la educación para/con/desde los pueblos y las comunidades indígenas o las minorías étnicas para otros contextos educativos iberoamericanos. Pretendemos hacerlo desde la especificidad histórica didáctica y pedagógica que caracteriza a la Universidad Intercultural del estado de Puebla en su sede sur, enclavada en el municipio de Tlacotepec de Benito Juárez, en la región ngigua poblana[1]. Para ello, haremos uso del análisis de estrategias colaborativas impulsadas por estudiantes de cuarto semestre de la licenciatura en Lengua y Cultura que relatan aspectos de la cultura ngigua del semi-desierto poblano en contextos sindémicos; la "Mano vuelta" (thengijna chooni naa ko naa ni) o la "promesa" (thi tenkininxini sincheeni), como formas de relatar y acompañar las críticas al extractivismo en todas sus formas, alimentando una reflexión situada desde el 
paradigma de la comunalidad (Diaz, 2014) en tres horizontes; prácticas de soberanía alimentaria, radio educativa comunitaria y resistencia al imperialismo energético.

En nuestro análisis queremos relacionar las consecuencias del imperialismo energético (Vega Cantor, 2017) en la región ngigua poblana con las formas comunitarias como la manovuelta (Thengijna chooni naa ko naa ni en la lengua ngigua) que despliegan toda una economía política educativa de los afectos y los cuidados desde los valores de uso.

Aunado a lo anterior no podemos soslayar que la región ngigua poblana, contexto socio-histórico de nuestra reflexión, es una zona de índice de vulnerabilidad alto, muy alto y crítico (Suárez L., Valdés G., Galindo P., 2020)[2]], dónde confluyen dimensiones demográficas, de salud y socioeconómicas que vuelven a sus habitantes propensos a no poder afrontar una infección como es la del COVID-19 con las mejores herramientas a su disposición. Por lo que adentrarnos en cuáles han sido algunas estrategias socioculturales que los habitantes de esta región biocultural de nuestro estado de Puebla han implementado desde febrero de 2020[]ㅡ son cruciales para nosotros, en aras de alimentar lo que nosotros llamamos una pedagogía no totalmente subsumida a los valores de cambio. En este tenor caber mencionar que nosotros utilizaremos la palabra sindemia por el hecho de reconocer que existen problemas de salud sinérgicos que afectan la salud de una población en sus contextos sociales, culturales y económicos y que permiten reunir en nuevas categorías de estudio,- que concilian lo biológico con lo social-, los factores de riesgo que nos permiten anticipar e implementar programas de prevención e intervención para abordar las comorbilidades como ejes transversales que atraviesan fenómenos pandémicos coyunturales.

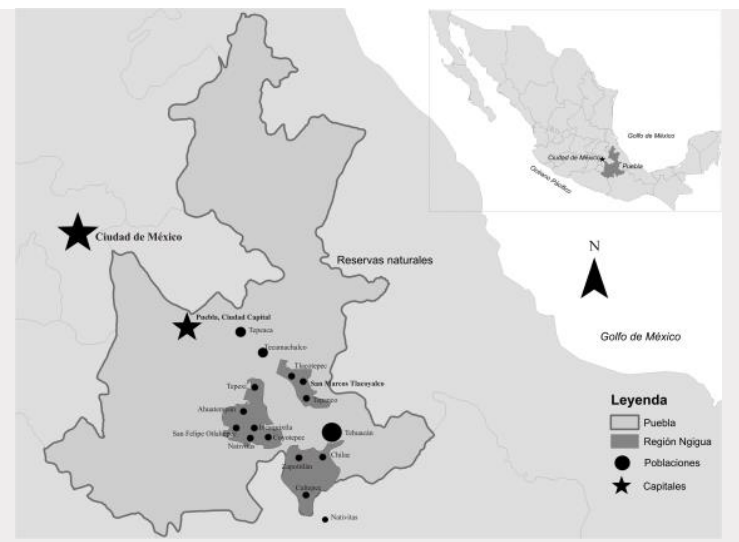

Figura 1: Región ngigua

Elaboración de Sabino Martínez Juárez (2020)

Este texto evocará estrategias situadas de la milenaria cultura ngigua[4]; "Mano vuelta" (thengijna chooni naa ko naa ni) o la "promesa" (thi tenkininxini sincheeni), desde la "comunalidad ngigua" rajnanee ni, que se vienen gestando como anticipaciones oníricas para hacerle frente a la industria bélica y carcelaria de vigilantismo sanitario 
que se instala en nuestros cuerpos con sus narrativas de higiene, violencia, distanciamiento y muerte. Para poder situar, lo que consideramos son algunos debates que han podido activarse fervorosamente durante los meses que han transcurrido las lógicas de distanciamiento social y que tienen que ver con el acceso a un alimento no totalmente domeñado por las lógicas de imperialismo energético instalado en nuestras comunidades y la producción de contra-pedagogías dialógicas. En una conversa especular queremos con aquellos antecedentes plantear algunas estrategias desde el don comunitario que pudieran interpelarse en otras regiones con alta, muy alta o crítica vulnerabilidad sindémica ante el COVID-19.

En este tenor, nosotros entendemos por "imperialismo energético" el planteamiento de Renán Vega Cantor (2017) que problematiza los límites del capital desde una crítica situada en la teoría de valor de Marx (2008), visibilizando las lógicas criminales de la forma mercancía (Capitaloceno) como aquella matriz de muerte causante de la catástrofe ecológica que habitamos y que cobra múltiples rostros depredando, expropiando y expoliando las capacidades de las comunidades de producir experiencias por fuera de la forma de su reproducción, acumulación y circulación. Consideramos además que, el pensamiento del intelectual colombiano Renán Vega, nos permite reflexionar que la pandemia es el capital. Que la sindemia de COVID-19 es solo un rostro de la hidra cuyas innumerables cabezas toca desmontar, subvertir y horadar. En este tenor, el estudio de una región cultural como la ngigua en el estado de Puebla, nos permite comprender de que forma se afrenta incesantemente la capacidad de construir autonomía energética, alimentaria o pedagógica entre los pueblos originarios de nuestro país y nos urge, en el espejo de alternativas concretas, a plantear caminos que pregunten desde un mundo que no se contenta con las lógicas de muerte y violencia que padecemos. Para todos y todas aquellas y aquellos que han fallecido recientemente y que murieron sabiendo que aquello que amaron en vida sobrevivirá a la podredumbre del escarnio y el olvido. A los asfixiados por este mundo que nos vuelve números y no lugares, a los desesperanzados les dedico las siguientes palabras.

\section{Metodología}

La investigación fue de corte cualitativo e inductivo, mediante la sistematización de experiencia que despliega vínculos y tramas clave desde una subjetividad situada, en nuestro caso, la comunidad ngigua[]ㅡ de San Marcos Tlacoyalco en el municipio de Tlacotepec de Benito Juárez, sede de la Universidad Intercultural del estado de Puebla. Desde la subjetividad reflexiva escuchada consideramos es posible establecer relaciones susceptibles de estudiarse en otros casos. Se utilizaron también herramientas provenientes de las ciencias sociales, como la etnografía, la observación participante, la recolección de artefactos como las historias gráficas y las entrevistas. En nuestra investigación partimos del supuesto que estudiar los procesos que afrentan la posibilidad de construir autonomía energética, pedagógica o alimenticia y las resistencias y estrategias en comunidades de hablantes de lenguas originarias como la comunidad ngigua poblana, nos permitirá plantear iniciativas de salud comunitaria 
postcovid que consideren aspectos demográficos, de salud y socioeconómicosculturales a manera de horizontes de impugnación de las lógicas capitales, patriarcales y coloniales que atraviesan los proyectos extractivistas en la región y agudizan los índices de vulnerabilidad pandémica, incluyendo el horizonte educativo expresado en la brecha digital[6]. Bajo esta premisa de investigación pudimos revelar cómo en la región ngigua poblana se expresan al menos cuatro formas de vulneración de la economía política alimentaria que contextualizan los desafíos y determinantes, incluso, de la existencia misma de la cultura y lengua ngigua en el horizonte de su propia devastación y vulnerabilidad ante la nueva pandemia de COVID-19. La pregunta central de investigación es: ¿De que forma, a través de estrategias pedagógicas no totalmente subsumidas al capital, se hace frente al imperialismo energético en la región ngigua del estado de Puebla y de que forma los habitantes de la región acuerpan la interculturalidad? Algunas preguntas subsecuentes son: ¿Qué desafíos nos presenta la actual coyuntura sindémica con respecto al estudio de la cultura alimenticia entre los pueblos originarios o las propuestas pedagógicas alternativas? ¿En qué términos podemos reflexionar las alternativas concretas de la "mano vuelta" o la "promesa" subvierten las lógicas de los proyectos extractivistas epistémicos?

La información recabada durante los últimos doce meses se baso en entrevistas a profundidad y semi-estructuradas de forma remota por las razones del aislamiento por la pandemia de COVID19 en la plataforma Whatsapp, Meet y Zoom y los primeros meses en estancias con los actores comunitarios como profesor investigador de la Universidad Intercultural del estado de Puebla (México) en comunidades ngiguas, en particular, en San Marcos Tlacoyalco[]]. (Ver Figura 2).

\begin{tabular}{|c|c|c|c|c|c|}
\hline Nombre & Edad & Ocupación & $\begin{array}{l}\text { Estatus } \\
\text { Social }\end{array}$ & Formación & Lugar de origen \\
\hline $\begin{array}{l}\text { Ricardo } \\
\text { Juárez }\end{array}$ & 50 & Juez de paz & Casado & Constructor & San José Buenavista \\
\hline $\begin{array}{l}\text { Antonio } \\
\text { López }\end{array}$ & 20 & Estudiante & Soltero & Estudiante & San José Buenavista \\
\hline $\begin{array}{l}\text { Jesusa } \\
\text { Martinez }\end{array}$ & 45 & $\begin{array}{l}\text { Trabajadora, } \\
\text { estudiante y ama } \\
\text { de casa }\end{array}$ & Casado & Estudiante & $\begin{array}{l}\text { San Marcos } \\
\text { Tlacoyalco }\end{array}$ \\
\hline $\begin{array}{l}\text { Eufremio } \\
\text { Juárez }\end{array}$ & 45 & $\begin{array}{|ll|}\begin{array}{l}\text { Trabajador } \\
\text { estudiante }\end{array} & \mathrm{y} \\
\end{array}$ & Casado & Tlachiquero $^{1}$ & $\begin{array}{l}\text { San Marcos } \\
\text { Tlacoyalco }\end{array}$ \\
\hline $\begin{array}{l}\text { Linda } \\
\text { Martinez }\end{array}$ & 35 & Profesora & Casada & Maestra rural & $\begin{array}{l}\text { San Marcos } \\
\text { Tlacoyalco }\end{array}$ \\
\hline $\begin{array}{l}\text { Eligio } \\
\text { Juárez }\end{array}$ & 45 & Radialista & Casado & Ingeniero & \begin{tabular}{|ll} 
San & Marcos \\
Tlacoyalco & \\
\end{tabular} \\
\hline $\begin{array}{l}\text { Rocio } \\
\text { Hernánde } \\
z\end{array}$ & 20 & $\begin{array}{l}\text { Trabajador y } \\
\text { estudiante }\end{array}$ & Soltera & $\begin{array}{l}\text { Trabajador } \\
\text { y estudiante }\end{array}$ & Santa María La Alta \\
\hline $\begin{array}{l}\text { Abigail } \\
\text { Hernánde } \\
z\end{array}$ & 20 & $\begin{array}{l}\begin{array}{l}\text { Trabajador } \quad y \\
\text { estudiante }\end{array} \\
\end{array}$ & Soltera & $\begin{array}{l}\text { Trabajador } \\
\text { y estudiante }\end{array}$ & Santa Maria la Alta \\
\hline $\begin{array}{l}\text { Estrella } \\
\text { Ávila }\end{array}$ & 20 & $\begin{array}{l}\begin{array}{l}\text { Trabajador } \\
\text { estudiante }\end{array} \\
\end{array}$ & Soltera & $\begin{array}{l}\text { Trabajador } \\
\text { y estudiante }\end{array}$ & \begin{tabular}{|ll} 
San & Marcos \\
Tlacoyalco & \\
\end{tabular} \\
\hline
\end{tabular}

Fuente: Elaboración personal de Guillermo López Varela.

Figura 2: Información sobre los actores comunitarios Elaboración personal de Guillermo López Varela. 


\section{Desarrollo}

Don Miguel León Portilla en su capítulo "La meta de la educación entre los nahuas" de su pionera obra, La filosofía náhuatl estudiada en sus fuentes, señala que:

Así como en la Paideia de los griegos se acentuaba probablemente más el carácter personalista, así entre los nahuas, especialmente en el imperio az- teca, se atendía de preferencia al segundo aspecto de la educación: el de la incorporación de los nuevos seres humanos a la vida y objetivos supremos de la comunidad. Esta idea, que pone de relieve el carácter comunitario de la Tlacahuapahualiztli, no debe, sin embar- go, hacernos pensar en una absorción de la personalidad: rostro y corazón, por parte del grupo. Porque, en contra de esto, encontra- remos el testimonio de los textos que vamos a estudiar y que expre- samente hablan de una cabal formación del rostro y el corazón (León Portilla, 2017, p. 272).

Recordándonos que la meta de la educación entre los pueblos que han habitado desde hace milenios Mesoamérica, es la formación tanto de un rostro, (in ixtli) como de un corazón (in yolotl), constituyendo metáforas que tienen que ver con una educación integral, que apela a procesos racionales pero también sensitivos y dialógicos, dónde "la formación del rostro propio y ajeno" (Tlacahuapahualiztli) tiene que ver, con procesos colaborativos/comunitarios en los que uno involucra la dignidad del lugar del otro, su mirada, sentir y existir.

En este orden de ideas, hay dos conceptos de lucha en la región ngigua poblana (thengijna chooni naa ko naa ni, thi tenkininxini sincheeni) que consideramos pueden darnos luces en torno a qué estrategias pedagógicas han sido impulsadas para afrontar las lógicas sindemicas como forma de expropiación de la capacidad de lucha colectiva y como formas de cultivar la cercanía en el mundo. Las dos formas de experiencia ngigua que relataremos provienen de la necesidad cada vez más consciente en las comunidades humanas de que la forma de producir nuestros conocimientos, cómo los atesoramos y cómo los compartimos es la pregunta central de todo proceso de insubordinación a un sistema que nos quiere invisibles, que nos concibe residuales y nos anticipa como cadáveres.

Implican tomas de conciencia por parte de los sectores populares organizándose en tramas de subsistencia para criticar las formas sociales que acosan, violentan e impiden la reproducción de la vida propia y la de las familias comprometidas por lógicas de extractivismo epistémico. En este orden de ideas, en un nivel filosófico político lo que consideramos articularía estos dos conceptos vivenciales sería la producción de afinidades determinantes y condicionantes de la indómita revuelta de las comunidades al mirar,- desde las problemáticas sociales que produce la pandemia-, lo que nosotros llamamos una pedagogía del apapacho[]. Una pedagogía a contra corriente de la historia hegemónica que produce relaciones sociales no totalmente mediadas por la forma mercancía, los valores de cambio o relaciones de extractivismo epistémico y que 
se preocupa por establecer relaciones de reciprocidad, escucha, diálogo, cooperación, solidaridad, dónde formarse colectivamente desde un rostro y corazón común implica la meta más alta de un proyecto colectivo.

Nosotros concebimos que la "pedagogía del apapacho" atraviesa la problematización de las intervenciones que relataremos, a manera de huellas de procesos sociohistóricos dinámicos, complejos y polivalentes. Repletos de material de ruptura por correspondencia al material constitutivo del tiempo y el espacio del capital y sus pandemias. ¿Cuáles serían algunas afinidades que tejen la experiencia pedagógica de la "Mano Vuelta" o la "Promesa"? En nuestra perspectiva serían las siguientes y podríamos considerarlas como un proyecto de lucha para los escenarios que la forma pandemia nos ha impelido a reflexionar y que consideramos deben ser discutidas a la luz de la experiencia histórica en la región ngigua poblana:

- El convencimiento de la necesidad de preponderar los valores de uso a los valores de cambio (ganancia).

- Las estrategias pedagógicas hegemónicas parten de lógicas extractivistas que no han podido dejar de concebir a los sujetos como objetos de estudio

- Una pedagogía no totalmente subsumida a las lógicas patriarcales, coloniales y capitales es posible.

¿A qué apelamos cuándo hablamos de extractivismo desde una perspectiva energética o alimentaria? ¿Qué implicaciones tiene en los proyectos educativos en la región ngigua poblana? Nosotros, vemos instalarse en la región ngigua poblana (San Marcos Tlacoyalco, Tlacotepec de Benito Juárez) y por extensión en el valle de Tehuacán, algunos de los escenarios siguientes:

1) La creciente implantación de agendas de siembra de monocultivos ligados a industrias culturales, verbigracia los agaves pulqueros, mezcaleros o el propio maíz nativo en la región donde fue domesticado hace miles de años.

2) El nulo planteamiento de alternativas al auge de granjas porcícolas y avícolas (monocultivos industriales de productos cárnicos[]]) como industria extractiva que produce el mayor número de gases de efecto invernadero e interioriza en el ámbito campesino la industria militar para la muerte y familiariza a las comunidades con lógicas genocidas. Pudiendo, como ya ha ocurrido en ocasiones anteriores, encarnar focos de infección de virus y coronavirus[10] como se ha documentado anteriormente en regiones como la del municipio de Perote en Veracruz para el caso del virus H1N1[11].

3) La creciente presencia de formas de renta de la tierra transnacional (capital chino) para sembrar con agro tóxicos y que constituyen formas de guerra contra los cultivos 
nativos e instauran formas de expropiación globales en ámbitos locales a manera de nuevas relaciones de dependencia internacional. De igual forma, como correlato de la exacerbación del discurso anti-inmigrante y el agravamiento de las medidas represivas en EEUU contra nuestros connacionales, existe una situación de vulnerabilidad económica que viven jóvenes migrantes repatriados de EEUU (2017-2019) y sus familias, cuyo origen sociocultural son comunidades con un grado de intensidad migratoria medio (Índices de intensidad migratoria México-EEUU por entidad federativa y municipio. INEGI) , como el Municipio de Tlacotepec de Benito Juárez donde el $4.44 \%$ de los hogares recibe remesas de EEUU y $4.43 \%$ cuenta con migrantes que han retornado el quinquenio anterior.

4) Nuevas formas de la guerra desplegadas en la forma de aeronaves que impiden que se concentren las precipitaciones de agua en la región ngigua y que de acuerdo a investigaciones comunitarias por parte del "Frente en defensa del territorio y los recursos naturales Puebla-Oaxaca" (Camacho, 2020), pueden ser atribuidas a "Grupo Romero" una de las empresas productoras de huevo y carne de cerdo más importantes de México.

De esta forma, ahora nos toca referir algunas claves para senti-pensar de qué forma se ha hecho frente en la región ngigua poblana a los embates de la Modernidad capital, patriarcal y colonial que hemos evocado con anterioridad y plantear alternativas en torno a los límites del "imperialismo energético" (Vega Cantor, 2017) capitalista pandémico que expropia las capacidades pedagógicas de las comunidades de ser soberanas. Nosotros consideramos que lo que estamos atravesando actualmente es una crisis que puede ser explicada no solo por la presencia de un coronavirus en el globo sino por la exacerbación de las relaciones capitalistas de muerte para las que cada uno de nosotros no representa más que un recurso a usar y desechar. En la Universidad Intercultural del estado de Puebla-Tlacotepec pudimos darnos cuenta que nuestros estudiantes, después del cierre de muchos circuitos económicos, han tenido que asumir durante la pandemia trabajos de medio tiempo en la región, ayudando al incremento de los ingresos familiares y reactivando incluso circuitos migratorios a Los Cabos, Vallarta o Monterrey donde suelen trabajar, en particular, en el sector de la construcción y hemos tenido que diseñar actividades asincrónicas para que puedan realizarlas por la noche o los fines de semana. De igual forma, hemos flexibilizado las formas de entrega de las evidencias de actividades; fotografía a su cuaderno de trabajo, audios, videos, teatro, composición de canciones, teatro y sobre todo los hemos impulsado a construir una identidad digital en redes sociales donde puedan compartir las reflexiones desde los contenidos que abordamos en las clases en plataforma Meet, Zoom, Moodle o Whatsapp y que registramos audiovisualmente para que los estudiantes puedan revisarlos cuando tengan un tiempo.

Por ello, procederemos a describir lo que consideramos han sido algunas medidas comunitarias que han podido fortalecer el campo ngigua en la coyuntura pandémica actual. En primer lugar, debemos referir que la "Mano vuelta" (thengijna chooni naa ko 
naa ni) o la "promesa" (thi tenkininxini sincheeni), constituyen formas de trueque y trabajo venerable compartido a nuestros semejantes sin alguna mediación dineraria (también llamado tequio, faena) y que se preocupan, en especial, por el cuidado de los abuelos y los infantes, fortaleciendo al tiempo los procesos de comunicación intercultural comunitaria. Estas formas han ayudado a los habitantes de Tlacoyalco a emerger fortalecidos como comunidades. En nuestra sede académica de San Marcos Tlacoyalco contamos con una mayoría abrumadora de mujeres, 70\% aproximadamente, de las cuales entre 4 y 7 por cada grupo son madres de familia. Hemos podido atestiguar que muchas de ellas se hacen cargo de la economía política de los afectos y los cuidados en la trama comunitaria y familiar a la que pertenecen. Si bien cuando están en clases presenciales dejan a sus niños o familiares que cuidan a resguardo de alguien más, ahora tienen que hacerse cargo no solo de llevar sus clases si no de garantizar que sus hijos también tomen las suyas, preparar los alimentos, ordenar y limpiar su espacio doméstico y garantizar la reproducción de la vida en sus entornos inmediatos y haciendo en múltiples ocasiones las "faenas" que sus compañeros hacían antes de migrar[12]. "Manos vueltas" (thengijna chooni naa ko naa ni), a manera de tramas articuladas que ofrecen espacios de venta solidaria sin intermediarios o brindan canastas solidarias durante las fiestas comunitarias donde se devuelven o comparten "promesas" que implican un don comunal cíclico como todo lo que transcurre en la mirada de la cultura ngigua .

Es paradójico que cuando el gobierno federal decreto la jornada nacional de sana distancia (23 de Marzo de 2020) en la comunidad ngigua donde se asienta nuestra Universidad Intercultural, San Marcos Tlacoyalco, comenzaba exactamente el ciclo agrícola anual por lo que fue muy difícil para las familias que dependen del trabajo de siembra y cosecha en terrenos de riego no acudir a hacer las faenas del campo correspondientes. De ello depende tener el alimento necesario para poder sobrevivir. Por lo que los comentarios que recibimos de nuestros estudiantes es que resultaría un desafío enorme no acudir a sus terrenos de cultivo, devolviéndonos con fuerza la idea de que el encierro en las circunstancias actuales es un privilegio y que, muchas veces, unos pueden guadarse por que otros no pueden dejar de salir. En este tenor, durante los primeros meses de la "jornada nacional de la sana distancia" les pedimos a nuestros estudiantes pudieran contarnos la forma en que estaban habitando sus tiempos y espacios de distanciamiento a través de "cartografías pandémicas" y encontramos en sus trazos, representaciones y preguntas escriturales horizontes que nos siguen interpelando. Nos hacían convencernos que más que intentar seguir un programa curricular habría que senti-pensar las necesidades humanas, vitales y emocionales de nuestros estudiantes para prodigar clases virtuales que propiciaran una educación bajo proyectos transgeneracionales que problematizaran e involucraran las experiencias, sentires, conocimientos y saberes de todos los miembros de las familias y alimentaran los vínculos comunitarios. Estamos convencidos que es posible elaborar estrategias docentes más específicas interpelando a nuestros estudiantes en torno a la forma en que producen el espacio y de esta forma permitiéndonos, por ejemplo, intervenir con mejores herramientas en lo que es el corazón de las Universidades Interculturales; la 
vinculación comunitaria. A través de la elaboración de estos mapas sensibles pudimos atestiguar que las emociones que expresan nuestros estudiantes son polivalentes, contradictorias y antagónicas. Consideramos que reflexionando la dimensión cartográfica de la lengua o la memoria pensamos que es posible construir relatos desde el ahora, repleto de imágenes en tensión, expresando las luchas inacabadas, que nos digan cómo hemos escrito nuestra historia, cómo pensamos el territorio, con qué herramientas, corpus de valores, y lugares de contemplación. Realizar, por ende, una labor arqueológica de la lengua, a través de cartografías y mapas participativos que potencien la capacidad de intervenir en el revelamiento de los procesos de vida y sus valores de uso, entre los habitantes de la región, tal y como ellos los refieran. Nosotros concebimos que construir una cartografía social de las emociones en contextos pandémicos nos ha permitido dejar de situar la acumulación capitalista como punto de partida, invisibilizando y negando la amplia galaxia de actividades y procesos materiales, emocionales y simbólicos que se realizan y despliegan en los ámbitos de actividad humana que no son de manera inmediata producción de capital. Fortaleciendo los lazos comunitarios. Por ende, las citadas cartografías fueron encomendadas a los estudiantes como un ejercicio y deber de memoria que pudiera dar cuenta de múltiples otras formas de habitar el espacio o de desplegar el territorio como una vivencia. De esta forma, subrayábamos la necesidad de alejarnos de experiencias cartografías que solo relatan la forma en que "verídicamente" el espacio es socialmente producido y les pedíamos a nuestros estudiantes nos contaran de qué modo podrían contarnos viven sus comunidades desde la creación de cartografías alternativas. Ejercicios en que no fuera relevante saber dónde se encuentra la escuela, el hospital o la plaza central sino saber dónde dieron un beso por primera vez, despidieron a un querido amigo o familiar entrañable, vivieron la muerte de un padre, una madre o un abuelito, fueron inmensamente felices o profundamente tristes. Los resultados del ejercicio desbordaron cualquier pronóstico y nos devolvieron la incesante responsabilidad de producirnos en el espacio educativo como un nosotros que precisa escribir, sentir, pensar el mundo desde los márgenes.

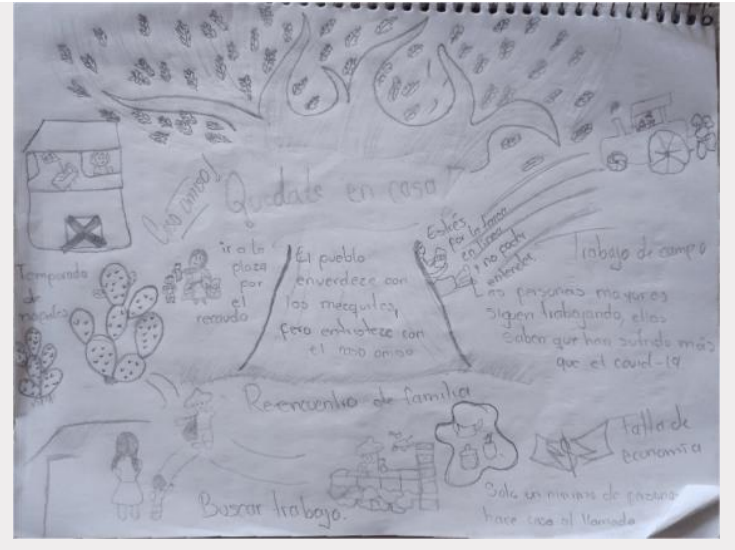

Figura 3: Cartografías pandémicas1

Estrella Ávila 
A la sombra de un árbol de mezquite, sagrado para la cultura ngigua, transcurren varias escenas en las que podemos atestiguar como la compañera Estrella Àvila de tercer semestre de la licenciatura en Lengua y Cultura, expresa su preocupación por los horizontes que atraviesan la experiencia pandémica en San Marcos Tlacoyalco. "El pueblo enverdece con los mezquites, pero entristece con el caso omiso" son palabras que condensan la recuperación del lazo ecológico con la apropiación del territorio; "trabajo de campo", "temporada de nopales" pero que lamentan el "caso omiso" de las personas que siguen sin poder guardar algún distanciamiento social. Nos demuestra cómo por la deteriorada economía "sólo un mínimo de personas hacen caso al llamado", se debe "buscar un trabajo" y las personas mayores de la comunidad siguen trabajando pues saben que se sufre más por hambre o pobreza que por una enfermedad que hasta entonces solo existe en las declaraciones de los políticos. Se demuestra como se dan "reencuentros familiares" posibilitados por el cierre de circuitos económicos y los migrantes retornan a la comunidad que un día los vió partir. Se representa la búsqueda de trabajo en el sector de la construcción, la segunda actividad económica más importante después de la actividad agrícola, en contextos de recesión y depresión económica. Finalmente se muestran a cada lado del árbol de mezquite las dos actividades prioritarias de nuestros y nuestras estudiantes; la reproducción de la vida expresada en la necesidad de "ir a la plaza por el recaudo" y la trama educativa caracterizada por el "estrés por la tarea en línea y no poder entender"

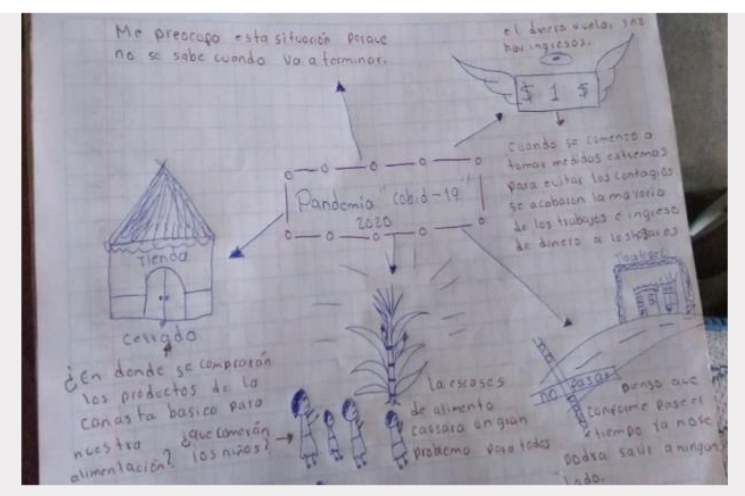

Figura 4: Cartografías pandémicas2

Abigail Hernández

Teniendo como centro de la representación una planta del sagrado maíz domesticado por la cultura ngigua, la compañera Abigail Hernández del tercer semestre de la licenciatura en Lengua y Cultura de nuestra Universidad Intercultural, nos expresa sus preocupaciones ligadas al ámbito económico político, dibujando una comunidad totalmente cercada, afrentada y clausurada en su vida comercial donde "el dinero vuela y no hay ingresos", "no se sabe cuando va a terminar" se acabaran la mayoría de los trabajos e "ingresos de dinero a los hogares" y finalmente se pregunta "¿Qué comerán los niños?" 


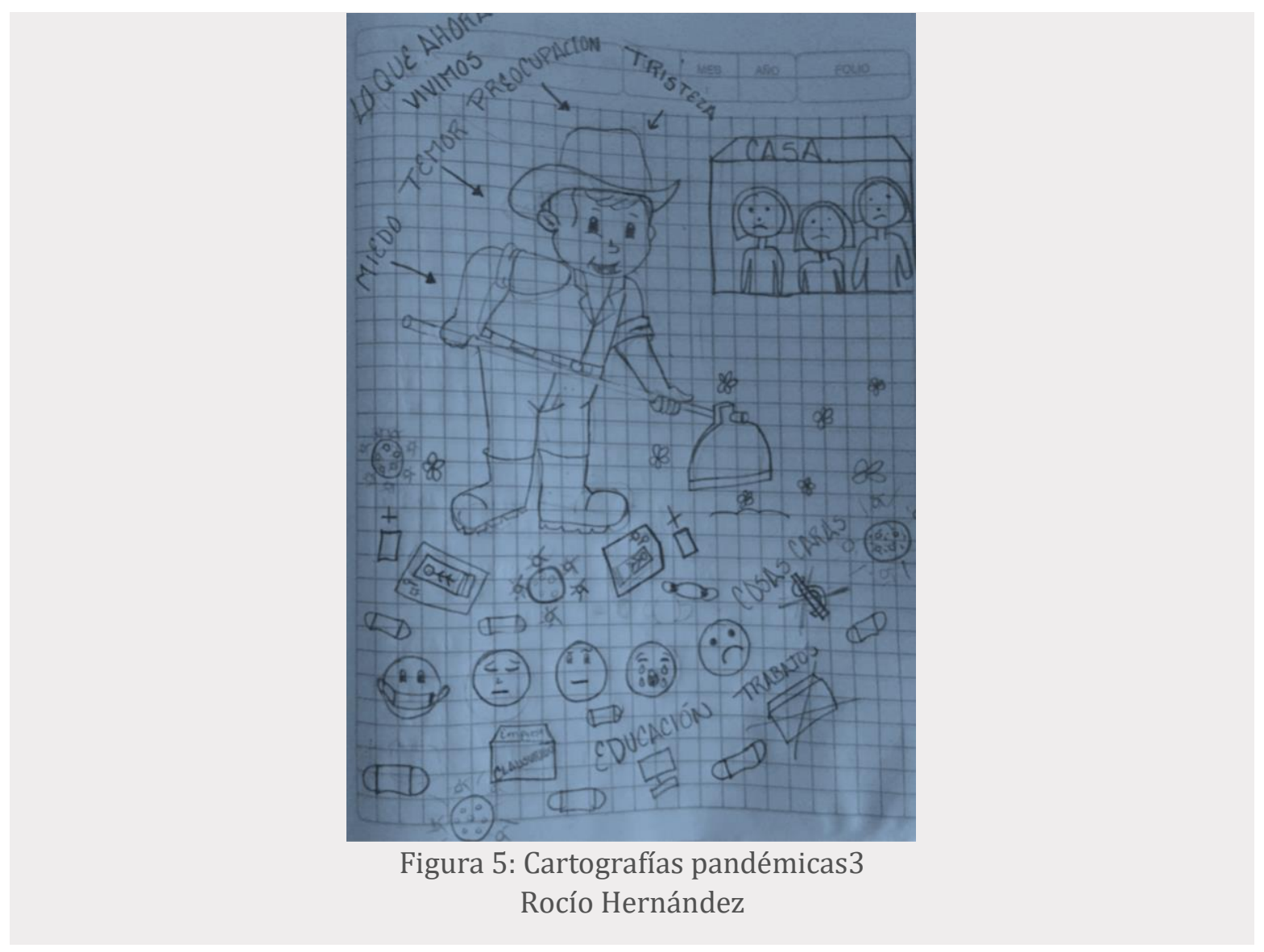

Mapas que como el de la compañera Rocío Hernández representan cómo los hombres siguen saliendo a hacer la faena del campo enmarcados por sentimientos de "miedo, temor, preocupación y tristeza" donde los trabajos escasean, las cosas se encarecen, los empleos desaparecen, las empresas cierran, las personas mueren y la educación en estos contextos se despliega como un cúmulo de emociones que cubren todos los espectros de la experiencia humana. Por las adversidades antes descritas, en el contexto sindemico ngigua se revelaron con profunda fuerza dos formas culturales que se cultivan como formas de gobernanza indígena y que tienen que ver con la producción de valores de uso y la socialización del trabajo colectivo "faena" o "tequio" encarnado en la forma de una "promesa" que vincula los ritos del ciclo agrícola. Una promesa es en palabras de la joven campesina ngigua Linda:

Son actos que se llevan a cabo por la religión católica en donde las manzanas (divisiones o unidades pequeñas que fueron hechas para abarcar más al pueblo y tener un control sobre la población y territorio). En cada año, por medio de un sorteo que se hace entre las manzanas, le corresponde a un santo para festejarlo en el día de su santa celebración, es por ellos que los integrantes de cada manzana se reúnen y se organizan para llevar a cabo dicho evento [13] 
Durante los días que dura la "promesa" se realizan múltiples actos donde se reparten las bondades y dones de la tierra que las familias de la manzana hayan podido consolidar durante el año agrícola. Las canastas solidarias son obsequios que los anfitriones preparan para los visitantes adicionalmente a los banquetes que durante los días que dura la celebración se efectúan. Este año para el caso de la celebración de la Virgen de Guadalupe que le correspondió a la manzana de la compañera Jesusa se repartió: "Antes de dejar la promesa a la iglesia, los comités preparan una comida para los invitados y a los que están colaborando con este acto, ofreciendo de comer un plato grande de frijoles refritos, arroz, tortillas grandes, mezcal y agua de Jamaica." Para el caso de la misma celebración pero para otra comunidad ngigua de la región (San Pedro Pericotepec), el compañero Eufremio nos menciona que durante las "promesas" y sus ritos y celebraciones se suele también disponer de un altar donde se conjuntan los dones de la tierra que la propia divinidad permite que los humanos disfruten. Nos comenta Eufremio:

En los altares tenemos los elementos principales de la naturaleza, que son: Tierra, Agua, Luz y Aire. Estos cuatro elementos son los principales para toda la cosecha, ya que sin agua la planta no crecería, sin luz no brotaría, sin aire no resistiría y sin tierra no se fortalecería. Posteriormente están algunas plantas en macetas, algunas de ellas son plantas medicinales (que utilizan algunas personas para hacer sus remedios caseros) y también hay plantas que son frutales las cuales nos alimentamos de ellas. También podemos observar cuatro colores de flor, las cuales son: blancas, rojas, amarillas y moradas, cada una marca los puntos cardinales, el blanco marca el norte, morado marca el poniente, el amarillo sur y el rojo oriente. Esto aparte de que se hizo para agradecer por las cosechas que se dieron, también es para que de agua para las cosechas, como lo dije anteriormente, es lo más principal, para fortalecer las cosechas, un ejemplo es de que en este año no se dio tanto las lluvias, y todos los agricultores sufrieron mucho por sequía, ya que sus cosechas se secaban y tenían perdidas, Esto es muy importante ya que sin esto habrían muchos problemas, este "ritual" mas que nada esta ofrenda se puede hacer cada ocho días, para darle gracias a dios por cada amanecer, por cada gota de agua, y porque nunca nos haga falta nada.

Es muy importante mencionar cómo los ritos y ceremonias son parte constituyente de la forma en que se construye gobernanza comunitaria entre la cultura ngigua. Los ritos agrícolas ligados a creencias previas a la imposición de la religión católica subsisten en el cumplimiento de "la promesa". Las celebraciones de los dones comunitarios decantados en los altares dispuestos para las fiestas son instantes que evidencian lo importante y urgente de la vida cotidiana; la algarabía derivada de la comunalidad dispuesta en el trabajo colectivo que brinda el alimento comunitario, la "mano vuelta" que posibilita un existir por afuera de las lógicas mercantiles y la fiesta como culminación y umbral donde es posible existir en un tiempo no lineal, no totalmente productivista o regido por las lógicas de la mercancía. Las promesas representan verdaderos altares a la autonomía alimentaria donde se recuerda lo 
importante y lo urgente, la necesidad de seguir cultivando, cocinando y comiendo aquello que los abuelos, los más antiguos nos enseñaron a habitar.

Tramando las iniciativas ciudadanas y emprendimientos sociales comunitarios evocados, consideramos podría promoverse la reivindicación de una forma socialnatural de la vida y su mundo de valores de uso, en medio de la catástrofe que sufren esos propios valores en los procesos de acumulación capitalista. Nosotros consideramos que estas iniciativas podrían promover la resistencia a una modernidad catastrófica, un rescate de lo concreto reafirmando el mundo de la vida en un plano de imaginarios, en medio de su propia devastación. Interpelando a Bolívar Echeverría (2000) estrategias de supervivencia dentro del capitalismo o como un modo de hacer vivible lo invivible de la represión cotidiana.

Como lo hemos mencionado, durante las lógicas de distanciamiento que ha prodigado la pandemia de COVID19, un elemento que ha posibilitado de la resistencia y sobrevivencia de las comunidades ngiguas ha sido seguir cultivando las formas tradicionales de trabajo colaborativo y de socialización del excedente económico decantado en las "promesas". Por ende, nosotros reivindicaríamos que no solo son eventos religiosos sino que son ante todo acontecimientos que posibilitan seguir "cultivando el vínculo" entre diversos núcleos familiares que han tenido distintos resultados derivados de su trabajo agrícola y encuentran en la comunalidad de la "promesa" la capacidad de salir delante de forma comunal.

De cara al contexto socio histórico descrito nosotros concebimos al proyecto de "canastas solidarias" encarnado en las promesas rituales anuales como un proceso comunitario que permite vincular a los productores de una región biocultural concreta con aquellos que quizás no han tenido el mejor año en sus cosechas y que han comprendido que la primera resistencia y organización comunitaria posible, atraviesa lo que comemos, de qué forma lo cultivamos y cómo lo compartimos. En aras de construir una sociedad donde todos puedan vivir dignamente y todos puedan comer alimentos sanos, locales y sin crueldad humana o no humana de por medio. En el esfuerzo de elaboración de la canastas solidarias durante los días de las "promesas" ngiguas podemos ver una esperanza entre los dientes, desplegándose como un anhelo que afirma la vida de cara a los múltiples procesos de muerte establecidos por el sistema mítico del capitalismo. Consideramos pues importante estudiar cuál es el papel de la acción humana en los esquemas de cuestionamiento de la dominación como en el sistema social vigente subsumido bajo la forma mercancía. Así, las canastas solidarias serían un modelo para la acción social de personas que han hecho de la esperanza organizada un modo de vida, el pensamiento en torno a los horizontes de esperanza dentro de esas acciones nos ayudará a entender cómo el sistema social vigente persiste, se fractura o se profundiza en las contradicciones.

Nosotros, nosotras consideramos que hay un lugar de memoria en los proyectos de las "promesas", como una de las artes de la vida cotidiana, que es capaz de devolvernos 
una imagen de nosotros mismos. Una imagen dialéctica que hace comulgar al pasado con el presente haciendo que estos tiempos colapsen en miles de astillas discontinuas e inquietantes a la memoria estática y celebratoria de los de arriba que siguen mirando a los de abajo con el desdén propio de quienes saben que no han dejado de triunfar. Desde abajo, con los múltiples valores de uso que celebran las estéticas políticas de la vida cotidiana se seguirán preservando, contradictoria y ambivalentemente, "leves fuerzas mesiánicas" (Benjamin, 2005), que anticipan un mundo que ya late dentro del nuestro donde es posible encontrar el rostro del otro, un otro, una otra que devendrá un nosotros.

Por todo lo anterior, nosotros consideramos que es muy necesario comprender de que forma en regiones como la ngigua en el estado de Puebla, se vienen activando estrategias desde los valores de uso que hacen frente a los remanentes del índice de vulnerabilidad que los constriñe a ser regiones afrentadas por la sindemia de COVID19. Como lo veremos en el apartado siguiente en torno a los medios de comunicación comunitaria lo que atestiguamos es el desmontaje por parte de los procesos organizativos ngiguas de uno de los pilares de la vulnerabilidad en el ámbito sociodemográfico frente a pandemias como la de SARSCOV2 y es el complicado acceso a materiales pedagógicos, documentales o informativos que aminoren la discriminación que podrían vivir la población indígena cuando intenta acceder a servicios de salud o a tratamientos médicos en sus propios valores socioculturales. Las estrategias de "mano vuelta" o las "promesas"[14] se podrían constituir en verdaderas alternativas a la precaria infraestructura sanitaria o la falta de personal médico brindando los recursos de trabajo colaborativo necesarios para su consecución.

\section{Conclusiones}

En nuestro artículo hemos abordado tres formas de trama ngigua que tienen que ver con las prácticas de soberanía alimentaria, radio educativa comunitaria y resistencia al imperialismo energético implantado en la región. La soberanía alimentaria de la región ngigua poblana se basa en las "promesas" como producción de valores de uso y la "mano vuelta" como intercambio de trabajo socialmente necesario para el articulamiento de una sociedad no totalmente subsumida al valor dinerario. La radio comunitaria ngigua ha devenido un importante gestor intercultural educativo para socializar los medios de comunicación comunitarios situados y pertinentes en la lengua originaria, así como brindar herramientas que permitan la producción de conocimientos, contenidos y experiencias relevantes para los habitantes de la región en su anhelo de seguir tramando un desarrollo endógeno en clave ngigua. La lucha por hacer frente al imperialismo energético en las cuatro vertientes que describimos en el texto surge desde la comprensión del jagüey como axis mundis comunitario, pues en los contextos de escasez de lluvia los procesos de organización comunitario han vuelto a reflexionar en torno a la importancia de proteger las obras hidráulicas que crearon sus ancestros. Al tiempo que fortalecen los procesos, herramientas y metodologías de participación en aras de construir una gobernanza autónoma y crítica ante las formas indigenistas que 
no dejan de ser alimentadas en la región. El intelectual mixe Floriberto Díaz Gómez (1952-1995) con su concepto de comunalidad ha sido un importante referente para atestiguar lo que venimos observando y relatando en nuestra reflexión. Con él, podemos decir que sigue siendo necesario desmontar la visión del poder que el Estado mexicano ha elaborado durante al menos los últimos dos siglos basado en el mito del mestizaje. Pues, los pueblos originarios siguen siendo vistos con desdén por aquellos que no pueden concebirlos como sujetos críticos y dignos de elaborar propias formas de gobernarse. Nuestro artículo en ese sentido permite mirar algunas formas comunales en las que, en la región ngigua poblana, se sigue produciendo una sociedad no totalmente subsumida a la relación museificada, patrimonializada, cosificada y fetichizada que se ha elaborado desde la forma "Estado mexicano" de las lógicas de gobernanza indígena tildándolas de "usos y costumbres". Misma mirada desdeñosa que no permite profundizar en un análisis serio de las prácticas históricas que han posibilitado su resistencia en el tiempo a pesar de las lógicas homogenizadoras de la cultura etnocéntrica y su matriz colonial, patriarcal y capital.

Nos urge sentipensar que el hacer vinculante de la comunidad ngigua que referimos; diverso, contradictorio y ambivalente no sólo produce cosas sino también lazos. Una noción revitalizadora que no pretende separar el trabajo productivo del reproductivo, la economía de la política o el ámbito "público" del "privado". Una noción de trabajo dinamizadora que surge del acuerpamiento para trastocar vigorosamente los asuntos públicos sin una perspectiva estado céntrica. Una noción de trabajo que nos urge a remontar el filo de la navaja entre (autonomía/estatismo) que marca las espacialidades y temporalidades de un binarismo excluyente para analizar los movimientos que subvierten el orden existente. Un análisis que no parte ya sólo de la acumulación capitalista, pues invisibiliza y niega el variopinto espectro de actividades y procesos materiales, emocionales y simbólicos que sostienen la vida cotidiana y no son de manera inmediata producción de capital. Entonces si la disciplina-trabajo alumbra lo que el cuerpo es, para nuestra reflexión, el sentí-pensamiento desde la comunalidad sería un modo de acercamiento al mundo por el cual el sujeto experimenta la capacidad de producirse como sublevado (mano vuelta y la promesa); posibilidades de salvación de la muerte administrada, burocrática, banalizada y cotidiana $o$ la prisión/cuerpo/resistencia de la disciplina del trabajo. En nuestra perspectiva, en el ombligo del ethos moderno capitalista, patriarcal y colonialista, podemos encontrar cómo se puede articular como vivible aquello que es invivible, a través de subsumir los potenciales creativos e imaginativos de los entramados sociales (comunalidad) a la voluntad destructiva inherente a la valorización del valor. Por ello, seguiremos indagando en la región ngigua poblana, contra-pedagogías del apapacho que desbordan y que desde sus remanentes de contemplación reb(v)elan la dimensión cualitativa de la vida y la negativa a aceptar el sacrificio de ella, a las lógicas de la usura, la violencia y la ganancia del tiempo y espacio del capital y sus pandemias o del capital como pandemia totalizante. 
En suma, lo que consideramos pueden permitirnos reflexionar las estrategias expuestas desde las comunidades ngiguas del sur de Puebla, es la urgencia de reivindicar que se otorguen sin paternalismos ni manipulación política formas de transferencia de recursos que permitan incorporar a los campesinos,-si así lo decidieran-, flujos de comercialización en mercados locales, regionales y globales, estrategias de fomento de la organización comunitaria y la proliferación de escuelas campesinas con enfoque intercultural que puedan incentivar la curiosidad científica y ventanas epistémicas donde las comunidades pueden verse reflejadas en los grandes procesos globales desde la propia producción de sus saberes, conocimientos y experiencias hasta ahora negados por la Modernidad-Capitalista. Formas de comunicación comunitaria que permitan acceder a los hablantes de lenguas originarias a los mandatos del gobierno en cuestión de educación, salud y alimentación en las propias lenguas en que hablan y comunican sus afectos, miedos y esperanzas, como es el tema pendiente del nuevo etiquetado a productos alimenticios procesados. [15] El acercamiento con las comunidades campesinas por parte de cualquier política sanitaria post-covid debe hacerse bajo un enfoque participativo, consultivo y situado con respecto a las condiciones en que se dan los fenómenos sociales en el ámbito ecológico que las circunda y contra toda forma de extractivismo académico, impulsado, por ejemplo, procesos de creación de bancos de semillas locales y regionales; en aras de conservar, documentar y analizar los ecosistemas y agroecosistemas bajo el enfoque de los valores de uso, el cuidado de los ancianos, el trueque y una economía de cuidado de los más desfavorecidos.

\section{Referencias}

Adorno, T. W. (2008). Dialéctica Negativa. La jerga de la autenticidad. Madrid: Akal

Adorno, Theodor W. y Horkheimer, M. (1990). Dialéctica del iluminismo. Trad. H.A. Murena. Buenos Aires: Editorial Sudamericana.

Agrupación lingüística popoloca. Mapa de la lengua. Disponible en http://atlas.cdi.gob.mx/?page_id=3426

Arizmendi, M. C., A. Valiente-Banuet, A. Rojas-Martínez y P. Dávila-Aranda. 2002. Columnar Cacti and the Diets of Nectar-Feeding Bats. En: Fleming, T. H y A. Valiente-Banuet. Edit. 2002. Columnar Cacti and Their Mutualists: Evolution, Ecology, and Conservation. The University of Arizona Press. Tucson USA.

Barrenechea, J., Gentile, E., González, S. y Natenzon, C. (2000). Una propuesta metodológica para el estudio de la vulnerabilidad social en el marco de la teoría social del riesgo. En Buenos Aires: Facultad de Ciencias Sociales, Universidad Autónoma de Buenos Aires. http://test6.pirna.com.ar/files/pirna/PONBarrenechea-Gentile-Gonzalez-Natenzon- 
Una $\% 20$ propuesta\%20metodologica\%20para\%20el\%20estudio\%20de\%20la\% 20vulnerabilid ad.pdf.

Benjamin, W. (2002). La dialéctica en suspenso. Fragmentos sobre la historia. Madrid, España: Arcis Lom.

Benjamin, W. (2005). Libro de los pasajes. Madrid: Akal Ediciones.

Berger, J. (2006). Con la esperanza entre los dientes. México: La Jornada Ediciones/Editorial Ítaca.

Bloch, E. (1979). El principio esperanza, II, Madrid: Aguilar. . (2017). ¿Despedida de la Utopía?. Madrid: A. Machado Libros.

Camacho, Zósimo. "Impedir que llueva: las multinacionales que juegan a ser dios". Contralínea. (Ciudad de México) 24 de Julio de 2020. Disponible en: https://www.contralinea.com.mx/archivo-revista/2020/07/24/impedir-quellueva-las-multinacionales-que-juegan-a-ser-dios/?fbclid=IwAR2TYSGCSkMHuP61PajrRz_-ZNOtjfONNOxaeLbh_GX--IQQjSsqyawwEY

Diaz, F. (2014). Floriberto Díaz. Escrito. Comunalidad, energía viva del pensamiento mixe. México: UNAM.

Echeverría, B. (2012). Valor de Uso y Utopía. México: Siglo XXI editores. (2000). La modernidad de lo barroco. México: Era.

Eventos de repatriación de mexicanos desde Estados Unidos, según entidad federativa de origen y sexo (2018). Disponible en: http://www.politicamigratoria.gob.mx/es_mx/SEGOB/Repatriacion_de_mexican os_2018

Gutiérrez, Raquel., Navarro Mina Lorena. y Linsalata, Lucía. 2017. Repensar lo político, pensar lo común. Claves para la discusión. En Modernidades Alternativas, Inclán, Daniel, Linsalata, Lucia, Millán, Márgara, México, UNAM-Ediciones del Lirio. Disponible en: https://kutxikotxokotxikitxutik.files.wordpress.com/2017/11/pensar-lopolitico-pensar-lo-comun_gutierrez-navarro-linasalata-clavescomunfinal.pdf

Hernández Alcantara, Martín. 2020. "Ippi: Lomas de Angelóplis, ejemplo de discriminación del morenovallismo a pueblos indígenas ", LA JORNADA DE $\begin{array}{lll}\text { ORIENTE, } & \text { Noviembre } & 22,\end{array}$ 
https://www.lajornadadeoriente.com.mx/puebla/angelopolis-discriminacionmorenovallismo/

Índices de intensidad migratoria México-EEUU por entidad federativa y municipio. INEGI. Indice de Intensidad Migratroria. Disponible en https://www.gob.mx/cms/uploads/attachment/file/114224/Indices_de_intensi dad_migratoria_Mexico_Estados_Unidos_2010_Parte4.pdf

Kracauer, S. (2008). La fotografía y otros ensayos. El ornamento de la masa I, Barcelona, Gedisa.

León Portilla, M. (2017). La filosofía náhuatl estudiada en sus fuentes. http://www.historicas.unam.mx/publicaciones/publicadigital/libros/filosofia/0 46_04_31_meta_educacion.pdf

Löwy, M. (2002). Walter Benjamin: Aviso de Incendio, una lectura de las tesis "Sobre el concepto de historia". Buenos Aires: FCE.

Marcuse, H. (2010). Eros y civilización. Madrid: Ariel.

Martínez, Regina, "La negra historia de granjas Carroll”. Proceso. (Ciudad de México) 4 de Mayo de 2009. Disponible en: https://www.proceso.com.mx/114913/lanegra-historia-de-granjas-carroll-2

Marx, C. (2008). El capital. Crítica de la economía política, México / Buenos Aires / Madrid, Siglo XXI.

Pacheco, Yomara. "Campesinos de Tehuacán rentan a chinos sus tierras y sus peones". Municipios. (Puebla) 3 de Octubre de 2019. Disponible en: https://municipiospuebla.mx/nota/2019-10-03/tehuacán/en-tehuacán-chinosrentan-campesinos-sus-tierras-ahora-son-peones

Por la redaccción,. "Drones revelan la catastrofe ambiental por las granjas porcícolas en México". Sin embargo (Ciudad de México) 25 de Julio de 2020. Disponible en: https://www.sinembargo.mx/25-072020/3829228?fbclid=IwAR3nYr_MVmaPrEus0wkQI15gCoxtGh_F4HK0_WgpPg EUWeGayNGSETDrtnE\#.Xx2FOFPtelo.whatsapp

Por la redacción, "Comunidades mapuches donaron 6 mil kilos de alimentos a vecinas que realizan una olla común en el sector San Antonio de Temuco". Somos noticia-Chile. (Santiago) 20 de mayo de 2020. Disponible en: https://www.somosnoticia.cl/comunidades-mapuches-donaron-6-mil-kilos-dealimentos-a-vecinas-que-realizan-una-olla-comun-en-el-sector-san-antonio-de- 
temuco/?fbclid=IwAR2WtZcFTVoHUhRWqaFg1lcKSN6iEpLpJd2JUXMWqwdsKBTJfbEQXqQnRk

Suárez L., Valdés G., Galindo P., Salvador G., Ruiz R., Alcántara-Ayala, López C., Rosales T., Lee A., Benítez P., M. C. Juárez G., Bringas L., Oropeza O., Peralta H.s.sepiy Garnica-Peña. (2020). Índice de vulnerabilidad ante el COVID-19 en México. Investigaciones Geográficas. DOI: dx.doi.org/10.14350/rig.60140 • E-PRINT e60140

Vega Cantor, R. (2017). Introducción al capitaloceno. Argentina, Buenos Aires: Herramienta.

\section{Notas}

[1] Por ejemplo, para el caso del estado de Puebla, según la encuesta censal (2020) del Instituto Nacional de Geografía Estadística e Informática (INEGI), del millón 94 mil 953 habitantes del estado de Puebla que provienen de un pueblo originario (Náhuatl, Totonaku, Ngigua, Ñañu, Mazateco, Ñu savi, Tepehua) y que pueden acceder a una educación universitaria, solo el 3\% de esa población juvenil indígena en Puebla accede a la misma. Lo que muestra la profunda disparidad que existe en el acceso a la educación universitaria por parte de los pueblos originarios. Ello se agudiza si mencionamos que, de acuerdo al Instituto Poblano de los pueblos indígenas (IPPI) , solo el 9\% del presupuesto estatal se destina a municipios indígenas.

[2] La UNAM ha desarrollado un índice de vulnerabilidad ante el COVID-19 a escala municipal en México, que parte de tres dimensiones; la demográfica, la de salud, la socioeconómica. Parte del supuesto metodológico de la teoría social del riesgo que plantea que las pandemias tienen efectos diferenciados en cada lugar y que éstos variantes según las determinantes socio espaciales, económicas y de salud de la población.

[4] La lengua ngigua proviene del árbol de lenguas otomangues. Siendo la lengua más hablada junto con el español en la comunidad de San Marcos Tlacoyalco, municipio de Tlacotepec de Benito Juárez en el sur del estado de Puebla, sede sur de la Universidad Intercultural del estado de Puebla desde la cual tejemos nuestras reflexiones.

[5] Cuando referimos a la comunidad ngigua estamos evocando a los nombrados desde la escala estatal nacional como "popolocas". Según el Atlas de los pueblos indígenas de México, los "popolocas" que habitan el Municipio de Tlacotepec de Benito Juárez son 15, 438. En Puebla, según el último censo consultado de INEGI (2010) de la población de 5 años y más hablante de lengua popoloca, existen 28, 783 habitantes, de los que 13, 868 son hombres y 14, 915 son mujeres. A nivel estatal un total de 601, 608 poblanos (11\% población total de la entidad) son hablantes de otras lenguas originarias (Náhuatl), (Popoloca (ngigua), Mazateco (Ha shuta enima), Totonaco, Mixteco (Ñuu savi), Otomí (hñähñú)). Los sujetos interpelados durante nuestra investigación provienen de las comunidades de de San José Buenavista, San Martín Esperilla, San Juan Zacabasco, San Francisco Esperilla, Reforma, Colonia Guadalupe, La Virgen, El Mirador, El Gavilán, Los Cerritos, Piedra Incada de la soledad, Rincón de Zompantle y Palo Verde. 
[6] Para el caso del valle de Tehuacán donde se encuentra la sede sur de la Universidad Intercultural del estado de Puebla, según la última encuesta nacional sobre disponiblidad y uso de tecnologías de la información en los hogares (EDUTIH) 2018, que tiene por cometido obtener información sobre la disponibilidad y el uso de las tecnologías de información y comunicaciones en los hogares y su utilización por los individuos de seis años y más de edad en México, solo el $25 \%$ de los hogares cuenta con un ordenador, por lo que los estudiantes tienen que usar un dispositivo móvil para poder estar en contacto con sus clases virtuales adquiriendo planes de telefonía móvil que son completamente inasumibles para afrontar sus clases semana con semana.

[7] A pesar de las lógicas de distanciamiento social derivadas de la pandemia, pudimos seguir en contacto con los actores comunitarios con quienes tejemos esta reflexión. En particular, los estudiantes de la Universidad Intercultural verdaderos líderes contemporáneos de los procesos que llevarán en los próximos años a las comunidades ngiguas a presenciar nuevas e inauditas articulaciones desde una comunalidad crítica y quienes también sirvieron como enlaces con los más adultos líderes comunitarios muchas veces no familiarizados con las plataformas digitales.

[8] Hemos elegido la palabra "apapacho" que es un nahuatlismo del habla mexicana que hace referencia a procesos de "cultivo de la cercanía”, "mantener juntos". Según Carlos Montemayor: 1.Acariciar o abrazar cariñosamente a alguien. 2. Mostrar amor por medio de cariños, besos y trato cuidadoso y delicado. 3. Hacer que una persona se sienta apreciada y tomada en cuenta. De pahpatzoa, ablandar la fruta con los dedos, sobar una fruta, o de pachoa, apretar o acercar algo a uno mismo (Montemayor, 2007).

[9] Como lo ha documentado la organización, Igualdad Animal México (Sin embargo, 25 de julio de 2020): "para producir un kilo de carne de cerdo, se necesitan 12 mil litros de agua potable. En cifras nacionales, la crianza de cerdos para consumo humano, representa la utilización del 4 por ciento de toda el agua potable renovable de nuestro país. Pero, además de gastar millones de litros de agua potable, esta industria la contamina. El mal manejo y la falta de tratamiento de las heces y orina de los animales es un importante factor de contaminación del suelo y del agua, y una fuente de enfermedades infecciosas para los humanos". Anualmente son asesinados mil 800 millones de animales para consumo humano en nuestro país. Vidas que pasan toda su vida confinadas en granjas, sometidas a prácticas atroces, crueles y que producen gases de efecto invernadero. La ganadería industrial en México no reporta la cantidad de gases, olores y partículas sólidas y líquidas que emite, ni las cantidades de agua o el manejo de residuos que precisan sus procesos.

[10] No se ha estudiado a cabalidad las implicaciones de un peligro latente. En la región ngigua cohabitan especies como el murciélago magueyero y las formas extractivas de las granjas porcinas y avícolas. En México, el entrañable pulque, tequila, mezcal y bacanora se debe al paciente trabajo de polinización del murciélago magueyero (Leptonycteris yerbabuenae), quien durante millones de años ha sabido elegir los mejores magueyes de los que luego se nutrirá libando de sus deliciosos néctares. El único mamífero volador en el planeta tierra que ha habitado múltiples ecosistemas durante algo más de 50 millones de años se ha diversificado en alrededor de 1,300 especies. Hoy, sabemos que muchas de sus especies se han visto amenazadas por la depredación de los ecosistemas que habitan, la alteración del uso de suelo de zonas naturales que habitaban y la creciente infraestructura urbana que ahora ocupa estas 
regiones. En México (Arizmendi, Valiente-Banuet, Rojas-Martínez y Dávila-Aranda. 2002), por ejemplo, habitan 12 de las 38 especies de murciélagos nectarívoros que viven en el continente americano. De ello deriva que en nuestro país exista la mayor diversidad de agaves en el mundo (200 especies), 75\% de las cuales son nativas de México y 69\% endémicas. ¿Estamos en la antesala de una nueva zoonosis productora de un futuro coronavirus, ahora en la región?

[11] No podemos olvidar que la propagación del virus de la influenza H1N1, comenzó en una región de granjas porcinas y avícolas en el municipio de Perote, Veracruz (La Gloria) en 2009. Aún cuando los habitantes de la región vinieran denunciando sistemáticamente las consecuencias extractivistas en la sociedad y la naturaleza de la industria cárnica de empresas como Granjas Carroll; fetidez en el aire, enjambres de moscas, contaminación de los mantos freáticos, pozos y lagunas, enfermedades respiratorias y de la piel. Martínez, Regina, "La negra historia de granjas Carroll”. Proceso. (Ciudad de México) 4 de Mayo de 2009. Disponible en: https://www.proceso.com.mx/114913/la-negra-historia-de-granjas-carroll-2

[12] A este respecto la política social actual del Consejo Nacional de Ciencia y Tecnología de México ha tenido un impacto muy fuerte para nuestras estudiantes. Pues aunada a la beca de "jóvenes sembrando el futuro" que reciben todos nuestros estudiantes, las jóvenes madres estudiantes de nuestro programa académico, también reciben el "Apoyo a Madres mexicanas Jefas de Familia para Fortalecer su Desarrollo Profesional”

[13] En san Marcos Tlacoyalco se cuenta con 23 manzanas, remenbranzas de los antiguos calpullis o tlaxilacallis (barrios) en los que se organizan desde hace milenios las comunidades mesoamericanas.

[14] Para Floriberto Díaz (2014, p.59-60), el tequio tiene diversas variaciones; como trabajo físico directo para realizar obras públicas, como ayuda recíproca, como formas de atender a los invitados en una fiesta comunitaria, denominadas fiestas patronales de santos católicos, de tal forma que los huéspedes no pasen hambre y sed. Entre una comunidad y otra también hay práctica de tequio a través de las bandas de músicos (bandas filarmónicas), por el cual una comunidad puede invitar a la banda de otra a su fiesta haciendo el compromiso de corresponder de igual forma para cuando se le invite. Tequio también es trabajo intelectual, esto es, poner al servicio de la comunidad los conocimientos adquiridos en las escuelas ubicadas fuera de ellas, ya que al momento de dotar de terreno, poner trabajo, así como aportar dinero cuando se construye la escuela local, la comunidad espera de cada uno de sus hijos que retornen a darles sus servicios.

[15] A este respecto la Universidad Intercultural del estado de Puebla se ha preocupado desde el comienzo de la pandemia por producir materiales didácticos e infografías que condensen, en las siete lenguas originarias que se hablan en nuestro estado de Puebla, las informaciones, indicaciones y estrategias que los gobiernos de los tres niveles se han esforzado por desarrollar. Sea este artículo una advertencia a seguir el mismo camino posibilitando en todo momento la capacidad de las propias comunidades de conocer estas informaciones en sus propios contextos lingüísticos y socioculturales.

[3] 27 de febrero de 2020, fecha de registro del paciente cero de COVID-19 